Rafidain Journal of Science

Vol. 29, No.2, pp. 39-50, 2020

DOI

https://rsci.mosuljournals.com

ISSN: 1608-9391 e-ISSN: 2664-2786

Received 27/4/2020 Accepted 3/6/2020
اخلاف نباتات البروكلي (Brassica oleracea var. italica) من تمايز كالس السيقان تحت الفقية لبادراتها

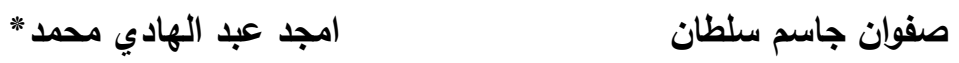
قسم علوم الحياة/ كلية العلوم/ جامعة الموصل / العراق

*E-mail: amjsbio33@uomosul.edu.iq

\section{الملخص}

انتجت الدراسة الحالية نباتات البروكلي (Brassica oleracea var. italica) من تمايز كالس السيقان تحت الفقية لبادراتها ونجاح اقلمتها ونقلها الى التربة. واوضحت النتائج Naphthalene acetic تباين نسب استحداث الكالس مع تباين نوع منظمات النمو النباتية ونئن Indole-3- 2,4-D) 2,4-Dichlorophenoxyacetic acid ، (NAA) acid (BA) Benzyl adenine وتراكيزها المستخدمة في هذا البحث. وكان لتداخل IBA مع BA الدور البارز في زيادة نسب الاستحداث. حيث تفوق وسط

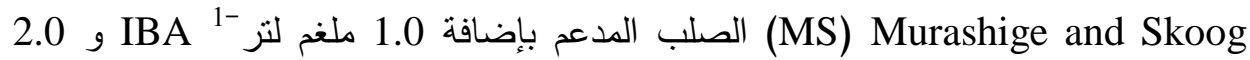
ملغم لتز

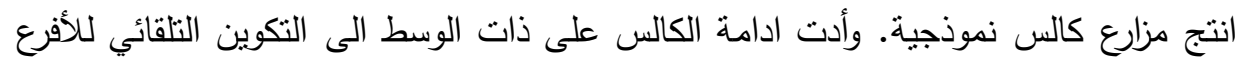

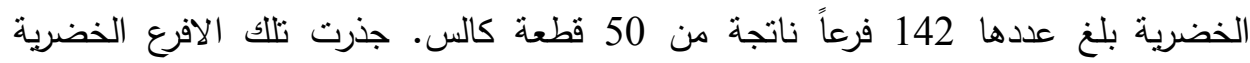
المتمايزة بسهولة في وسط MSO بكامل قوته التركيبية بنسبة 100\%، ومن لهن استمرار نموها وتكوينها مجاميع جذرية كفوة تمت اقلمتها بنجاح الى التربة ضمن سنادين في البيت الزجاجي. الكلمات الدالة: نبات البروكلي، مزارع الكالس، التمايز التلقائي للأفرع الخضرية، الاقلمة. 


\section{المقدمة}

يشير مصطلح زراعة الانسجة النباتية plant tissue culture الى زراعة اي جزء نباتي معقم خارج الجسم الحي

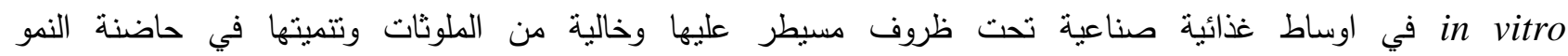

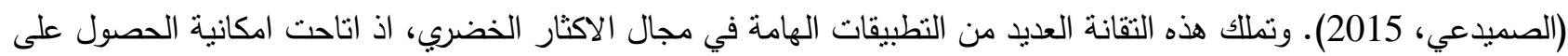
اعداد كبيرة من النباتات المتماتلة وراثبا، ذات مميزات مرغوبة وخالية من الامراض كبديل عن طرق الاكثار التقليدية

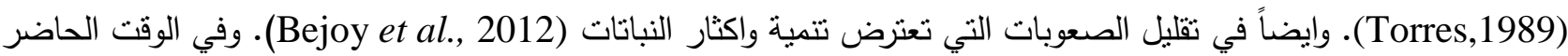
اتجه العلماء الى الاهتمام بتقانة زراعة الانسجة لعدد من النباتات الطبية لتأمين مركبات طبية وصيدلانية طبيعية وبنوعية وكمية جيدة على مدار العام دون التأثر بفصول السنة (Malabadi et al., 2011). وفتحت زراعة الانسجة النباتية ابواباً مشرعة لانبثاق الثثرة الخضراء الثابتة التي استخدمت فيها التحويرات الجينية والثقانات الحياتية المختلفة من اجل نوظيفها في مجال تربية

وتحسين النباتات كماً ونوعاً (Collen and Edward, 1998). تعود نبانات البروكلي Brassica oleracea var. italica الى العائلة الصليبية Brassicaceae ويسمى في الانكليزية Sporouting Cauliflower ، Asparagus Italian ، Broccoli

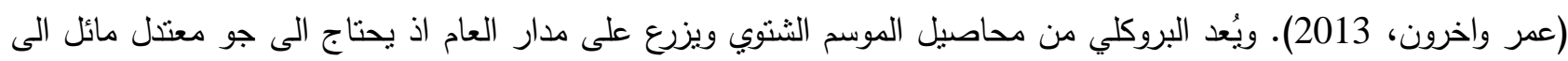

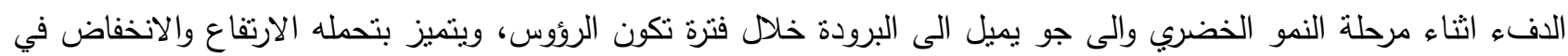

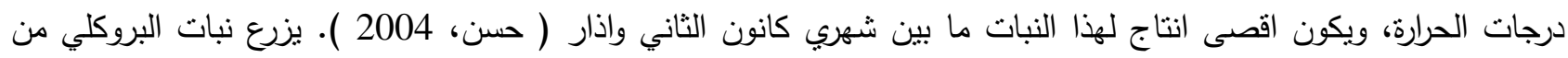
اجل نوراته التي تتراوح الوانها ما بين اللون الاخضر الى البنفسجي المخضر التي تؤكل وهي في طور البراعم الزهرية الخضرية مع حواملها السميكة الغضة، ويعد من اغنى محاصيل العائلة الصليبية مقارنة بالمحاصيل الاخرى (القرنابيط واللهانة واللهانة الصينية) من الناحية الغذائية واكثرها استخداماً من الناحية العلاجية في معظم بلدان اوربا، اذ تحتوي على العديد من العيد الفيتامينات

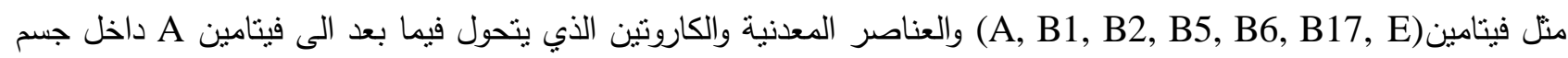
الانسان (Thapa and Rair, 2012). كما يُعد البروكلي من الخضروات ذات المحتوى العالي من فيتامين C وحامض الفوليك والنياسين والريبوفلافين والكاروتينات (Yoldas et al., 2008). ويُعد مصدراً غنياً بمركب السلفورافان (Sulforaphane) الذي مني

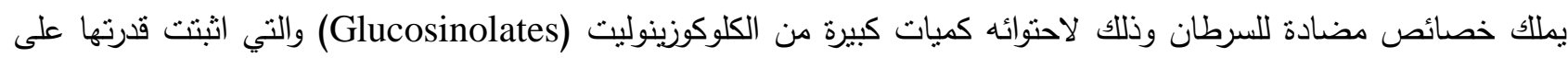
اختزال الخلايا السرطانية اذا لوحظ ان بإمكانها خفض خطر الاصابة بمرض السرطان بنسبة تصل الى 45\% كما يسهم ايضاً في

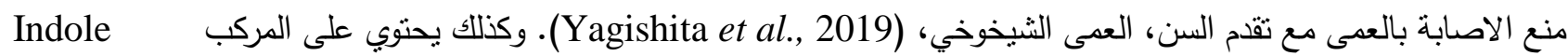
3- Carbinol .(Owis, 2015)

وللأهمية الغذائية والطبية لنباتات البروكلي فقد اجريت عليها العديد من البحوث لغرض زيادة انتاجها وتحسين صفاتها الزراعية من مزارعها النسيجية، وتمكنت احدى الدراسات من استحداث الكالس من قطع السيقان تحت الفقية لنبات البروكلي في

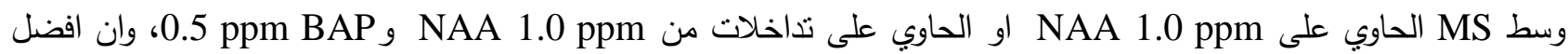
وسط لتمايز الافرع الخضرية كان وسط MS الحاوي على BAP 5.0 ppm لوحده (Tilaar, 1990). وفي دراسة اخرى نقلت قطع السيقان تحت الفقية لبادرات نبات البروكلي بعمر 7 ايام الى وسط MS حاوياً على نراكيز مختلفة من IBA و واظهرت النتائج الى ان افضلها لاستحداث الكالس هو الوسط المدعم بإضافة 3.5 ملغم لنز

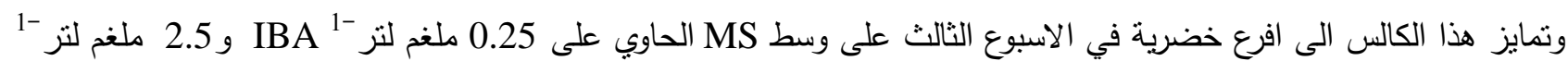

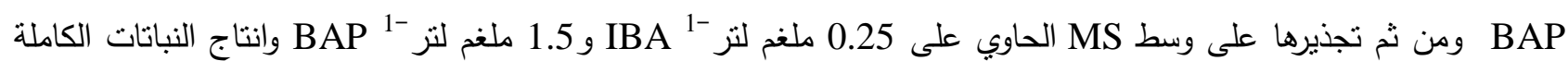
منها (Sharif Hossain et al.,2016a). واظهرت نتائج وضع قطع من فلق بادرات البروكلي بعمر 14 يوم على وسط 
مدعماً بإضافة منظمات نمو مختلفة، الى تكوين افرع خضرية مباشرة من تلك الفلق وان اعلى نسبة بلغت 90\% على وسط

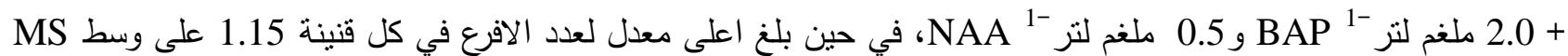
الحاوي BAP 1.0 ملغم لتز ${ }^{1-1}$ (Nazirwan,2015). وتهدف الدراسة الحالية الى امكانية استحداث الكالس من قطع سيقان تحت الفلقية والاوراق لبادرات نبات البروكلي Brassica oleracea var. italica المواد وطرائق العمل

\section{تعقيم بذور نبات البروكلي سطحياً وانتاج البادرات المعقمة}

جهزت بذور نبات البروكلي (Brassica oleracea var. italica) من الاسواق المحلية لمحافظة اربيل/ العراق وعقت سطحياً بغمرها في محلول الكحول الاثيلي 70\% مع التحريك المستمر لمدة دقيقتين، بعدئذ غمرت في 2\% من من محلول هايبوكلورايت الصوديوم NaOCl (القاصر التجاري /العملاق / صنع في الاردن) لمدة عشر دقائق. غسلت بعدها بالماء المقطر المعقم ثلاث مرات/ دقيقة (Kim et al.,2013). ولغرض التخلص من الماء الفائض عنها وضعت على ورقة ترشيح معقمة.

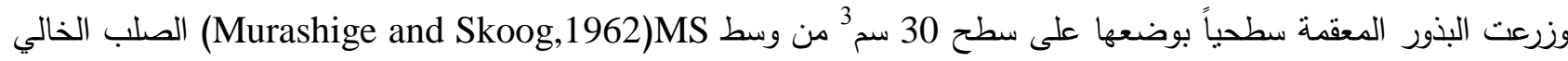

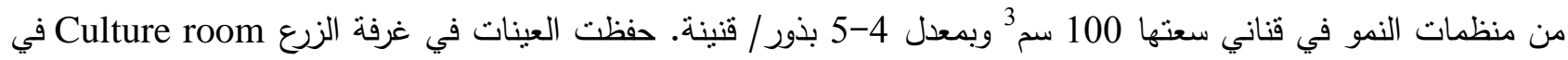
ظروف الظلام التام وبدرجة حرارة 242 سيليزية. وبعد ظهور الجذير والرويشة نقلت البادرات الناتجة الى ظروف الضوء المتعاقب 16ساعة ضوء / 8 ساعة ظلام وبشدة 2000 لوكس.

\section{استحداث الكالس من الاجزاء النباتية لبادرات نبات البروكلي}

رفعت بادرات نبات البروكلي Brassica oleracea var. italica السليمة بعمر 15 يوما من الوسط الغذائي. وعزلت سيقانها تحت الفقية بطول 1.5 سم تقريباً وفصلت اوراقها. ولغرض استحداث الكالس وضعت 3-4 من الاجزاء النباتية اعلاه المأخوذة من البادرات كلا على حدة على سطح 30 سم³ من وسط الاستحداث في قناني زجاجية بحجم 100 سم 100 وذلك باعتماد مكونات وسط MS اساساً ومدعماً بإضافات من منظمات النمو BA 2,4-D، IBA، NAA لوحدها او متداخلة فيما بينها MSO استتادا الى بحوث سابقة او منتخبة في هذه الدراسة وكما يلي:

$\mathrm{MS}+1.0 \mathrm{mg} \mathrm{L}^{-1} \mathrm{NAA}$

$\mathrm{MS}+2.0 \mathrm{mg} \mathrm{L}^{-1} \mathrm{NAA}$

$\mathrm{MS}+1.0 \mathrm{mg} \mathrm{L}^{-1} \mathrm{BA}$

$\mathrm{MS}+1.5 \mathrm{mg} \mathrm{L}^{-1} \mathrm{BA}$

$\mathrm{MS}+2.0 \mathrm{mg} \mathrm{L}^{-1} \mathrm{BA}$

(Sharif Hossain et al., 2016a)

$\mathrm{MS}+1.5 \mathrm{mg} \mathrm{L}^{-1} 2,4-\mathrm{D}$

$\mathrm{MS}+2.0 \mathrm{mg} \mathrm{L}^{-1} 2,4-\mathrm{D}$

$\mathrm{MS}+1.0 \mathrm{mg} \mathrm{L}^{-1} \mathrm{NAA}+1.0 \mathrm{mg} \mathrm{L}^{-1} \mathrm{BA}$

$\mathrm{MS}+1.0 \mathrm{mg} \mathrm{L}^{-1} \mathrm{NAA}+2.0 \mathrm{mg} \mathrm{L}^{-1} \mathrm{BA}$

$\mathrm{MS}+2.0 \mathrm{mg} \mathrm{L}^{-1} \mathrm{NAA}+1.0 \mathrm{mg} \mathrm{L}^{-1} \mathrm{BA}$

$\mathrm{MS}+2.0 \mathrm{mg} \mathrm{L}^{-1} \mathrm{NAA}+2.0 \mathrm{mg} \mathrm{L}^{-1} \mathrm{BA}$

$\mathrm{MS}+1.0 \mathrm{mg} \mathrm{L}^{-1} 2,4-\mathrm{D}+2.0 \mathrm{mg} \mathrm{L}^{-1} \mathrm{BA}$

$\mathrm{MS}+1.5 \mathrm{mg} \mathrm{L}^{-1} 2,4-\mathrm{D}+1.5 \mathrm{mg} \mathrm{L}^{-1} \mathrm{BA}$

$\mathrm{MS}+1.5 \mathrm{mg} \mathrm{L}^{-1} 2,4-\mathrm{D}+2.0 \mathrm{mg} \mathrm{L}^{-1} \mathrm{BA}$

$\mathrm{MS}+2.0 \mathrm{mg} \mathrm{L}^{-1} 2,4-\mathrm{D}+1.5 \mathrm{mg} \mathrm{L}^{-1} \mathrm{BA}$

$\mathrm{MS}+2.0 \mathrm{mg} \mathrm{L}^{-1} 2,4-\mathrm{D}+2.0 \mathrm{mg} \mathrm{L}^{-1} \mathrm{BA}$

$\mathrm{MS}+1.0 \mathrm{mg} \mathrm{L}^{-1} \mathrm{IBA}+2.0 \mathrm{mg} \mathrm{L}^{-1} \mathrm{BA}$

$\mathrm{MS}+1.5 \mathrm{mg} \mathrm{L}^{-1} \mathrm{IBA}+1.5 \mathrm{mg} \mathrm{L}^{-1} \mathrm{BA}$

$\mathrm{MS}+2.0 \mathrm{mg} \mathrm{L}^{-1} \mathrm{IBA}+1.5 \mathrm{mg} \mathrm{L}^{-1} \mathrm{BA}$

(Azis et al., 2015)

(Sharif Hossain et al., 2016b) 
تكوين مزارع كالس السيقان تحت الفلقية وادامتها نُقل الكالس المستحدث من القطع النباتية المستجيبة والمزروعة على بعض الاوساط الغذائية الى ذات الاوساط لغرض انتاج مزارعه وتمت ادامتها دوريا كل 20-25 يوما. تجذير الافرع الخضرية المتكونة تلقائياً استؤصلت الافرع الخضرية المتكونة تلقائياً من الادامة الدورية للكالس النامي على الوسط الغذائي MS ومدعماً بإضافة 1.0 ملغم لتز -

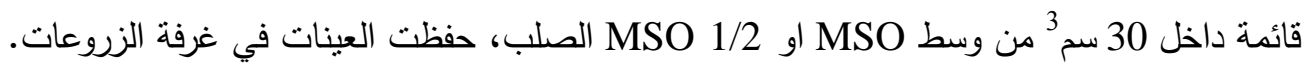
اقلمه نباتات البروكلي المتمايزة من كالس السيقان تحت القلقية الى الترية ازيلت النباتات الكاملة المتكونة في الاوساط الغذائية من الوسط وغسلت بالماء المقطر لإزالة بقايا الوسط ووضعت داتلة داخل

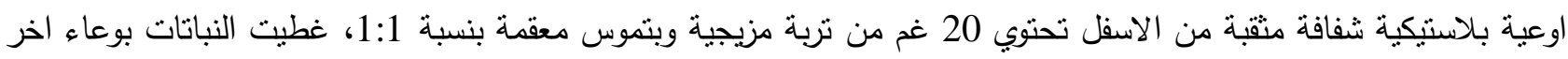
مع السماح بفراغ صغير بينهما. حفظت الاوعية في غرفة الزروعات بذات الظروف السابقة مع ملاحظة عدم جفاف التربة بالحفاظ ترنه على درجة عالية من الرطوبة لتجنب جفاف النباتات وموتها. وبعد زيادة عدد الافرع الخضرية ونموها ازيلت الاغطية وتركت بلته

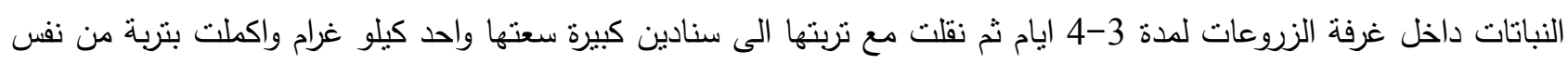

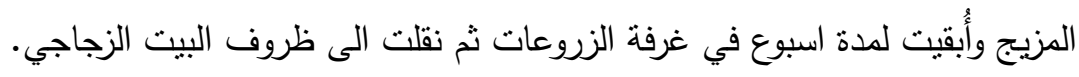

\section{النتائج}

كفاءة التعقيم السطحي للبذور وانتاج البادرات المعقمة

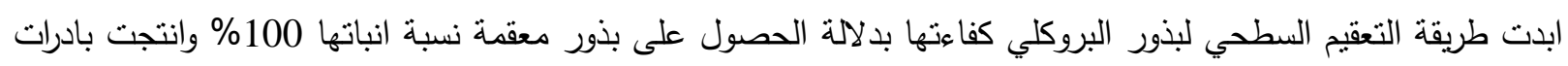

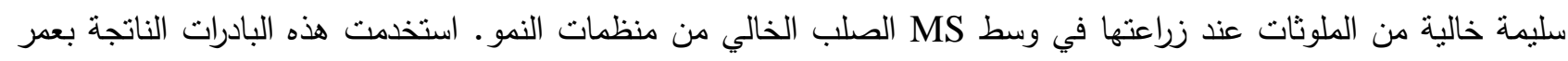
15 يوماً مصدراً للحصول على قطع السيقان تحت الفلقية والاوراق لاستحداث الكالس.

استحداث وتكوين مزارع الكالس من قطع السيقان تحت القلقية والاوراق اظهرت قطع السيقان تحت الفلقية والاوراق المستأصلة من بادرات البروكلي المعقمة قدرة منباينة لاستحداث الكالس عند عند

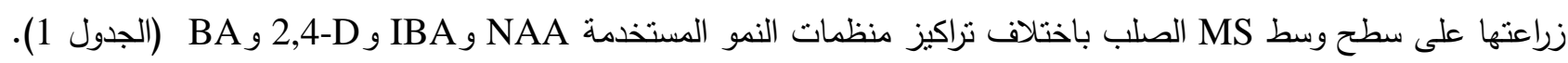

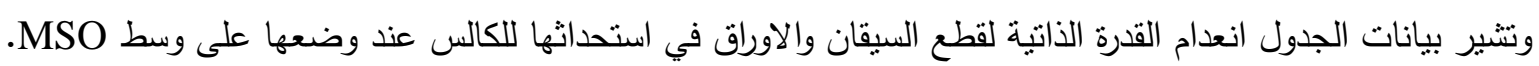

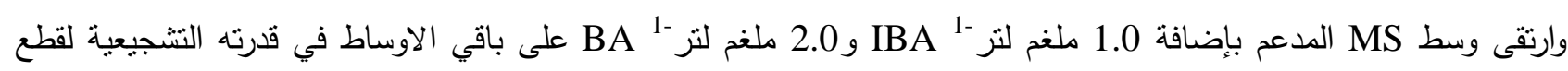
السيقان تحت الفقية المزروعة على الوسط الثكل(A.1) لاستحداث الكالس بنسبة 100\%، واستمرت خلايا الكالس المستحدثة بانقساماتها المتتالية مكونة كتلاً صغيرة من الكالس بعد 11 يوماً من الزراعة الثكل (B.1)، وتطورت لنتتج كتلاً اكبر حجماً بعد الندان

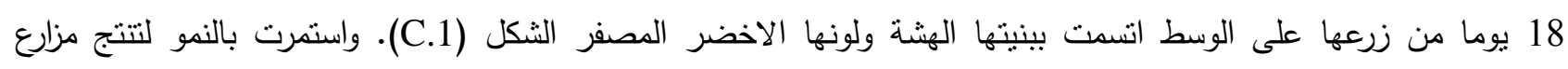
نموذجية من الكالس بمتاز بكتلته المتماسكة ولونه الاخضر المصفر بعد 30 يوما من الزراعة الثكل (D.1). 
Brassica oleracea var. الجدول 1: استحداث الكالس من الاجزاء النباتية المستأصلة من بادرات نبات البروكلي italica

\begin{tabular}{|c|c|c|c|c|c|c|}
\hline \multicolumn{3}{|c|}{ 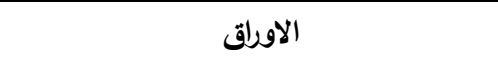 } & \multicolumn{3}{|c|}{ السيقان تحت القلقية } & \multirow[b]{2}{*}{$\begin{array}{c}\text { الوسط الغذائي مزوداً بمنظمات } \\
\text { (ملفم لتر -1) }\end{array}$} \\
\hline الاستحداث & استصداث & المزدروعة القطع & الاستحداث & الكالس (أتحداث & المزروعة / المستجيبة & \\
\hline 0 & 0 & $0 / 20$ & 0 & 0 & $0 / 20$ & MSO(المقارنة) \\
\hline 23 & 33.33 & $5 / 15$ & 17 & 58.33 & $14 / 24$ & $\mathrm{MS}+1.0 \mathrm{NAA}$ \\
\hline 0 & 0 & $0 / 14$ & 16 & 71.42 & $20 / 28$ & $\mathrm{MS}+2.0 \mathrm{NAA}$ \\
\hline 0 & 0 & $0 / 12$ & 25 & 16.66 & $4 / 24$ & $\mathrm{MS}+1.0 \mathrm{BA}$ \\
\hline 0 & 0 & $0 / 12$ & 16 & 31.25 & $10 / 32$ & $\mathrm{MS}+1.5 \mathrm{BA}$ \\
\hline 0 & 0 & $0 / 12$ & 0 & 0 & $0 / 25$ & $\mathrm{MS}+2.0 \mathrm{BA}$ \\
\hline 14 & 53.33 & $8 / 15$ & 13 & 54.54 & $18 / 33$ & $\mathrm{MS}+1.5$ 2,4-D \\
\hline 0 & 0 & $0 / 12$ & 14 & 75 & $27 / 36$ & $\mathrm{MS}+2.0$ 2,4-D \\
\hline 0 & 0 & $0 / 15$ & 19 & 70 & $21 / 30$ & $\mathrm{MS}+1.0 \mathrm{NAA}+1.0 \mathrm{BA}$ \\
\hline 0 & 0 & $0 / 15$ & 25 & 55.55 & $15 / 27$ & $\mathrm{MS}+1.0 \mathrm{NAA}+2.0 \mathrm{BA}$ \\
\hline 0 & 0 & $0 / 12$ & 18 & 60 & $18 / 30$ & $\mathrm{MS}+2.0 \mathrm{NAA}+1.0 \mathrm{BA}$ \\
\hline 23 & 40 & $6 / 15$ & 21 & 72.72 & $24 / 33$ & $\mathrm{MS}+2.0 \mathrm{NAA}+2.0 \mathrm{BA}$ \\
\hline 0 & 0 & $0 / 12$ & 18 & 83.33 & $20 / 24$ & $\mathrm{MS}+1.02,4-\mathrm{D}+2.0 \mathrm{BA}$ \\
\hline 16 & 66.66 & $8 / 12$ & 13 & 75 & $18 / 24$ & $\mathrm{MS}+1.52,4-\mathrm{D}+1.5 \mathrm{BA}$ \\
\hline$\overline{0}$ & 0 & $0 / 15$ & 21 & 75 & $18 / 24$ & $\mathrm{MS}+1.52,4-\mathrm{D}+2.0 \mathrm{BA}$ \\
\hline 14 & 20 & $3 / 15$ & 18 & 50 & $16 / 32$ & $\mathrm{MS}+2.02,4-\mathrm{D}+1.5 \mathrm{BA}$ \\
\hline 0 & 0 & $0 / 15$ & 15 & 72.72 & $24 / 33$ & $\mathrm{MS}+2.02,4-\mathrm{D}+2.0 \mathrm{BA}$ \\
\hline 18 & 14.28 & $2 / 14$ & 11 & 100 & $78 / 78$ & $\mathrm{MS}+1.0 \mathrm{IBA}+2.0 \mathrm{BA}$ \\
\hline 0 & 0 & $0 / 15$ & 12 & 90.90 & $60 / 66$ & $\mathrm{MS}+1.5 \mathrm{IBA}+1.5 \mathrm{BA}$ \\
\hline 0 & 0 & $0 / 15$ & 14 & 86.66 & $52 / 60$ & $\mathrm{MS}+2.0 \mathrm{IBA}+1.5 \mathrm{BA}$ \\
\hline
\end{tabular}




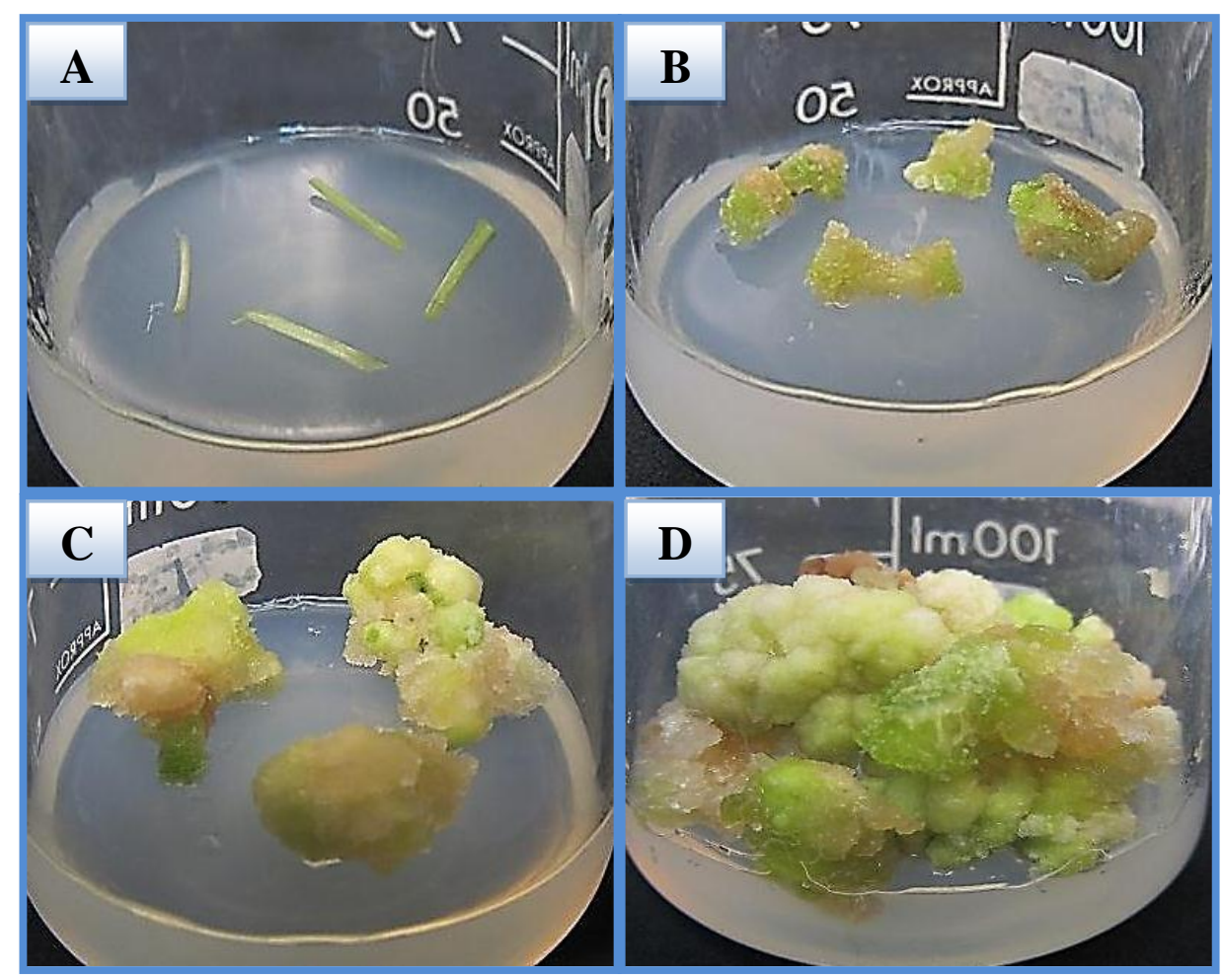

الثكل 1: تكوين مزارع كالس السيقان تحت القلقية لنبات البروكلي Brassica oleracea var. italica النامي على وسط

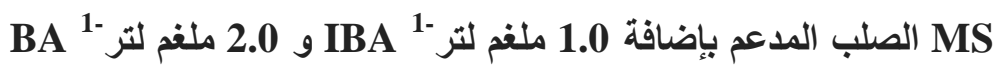

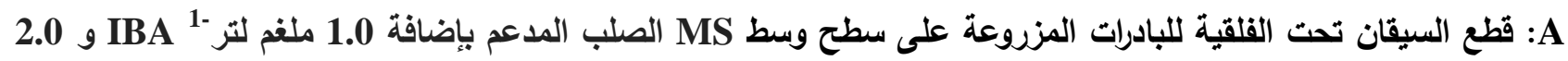
BA

B: استحداث الكالس وتكوينه كتلاً صغيرة من القطع في (A) بعمر 11 يوماً C تطور حجم كتل الكالس في (B) بعمر 18 يوماً: D : استمرار نمو الكتل في (C) وتكوينها مزرعة كالس السيقان تحت الفلقية بعمر 30 يوماً

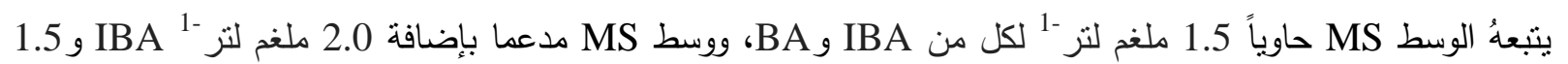

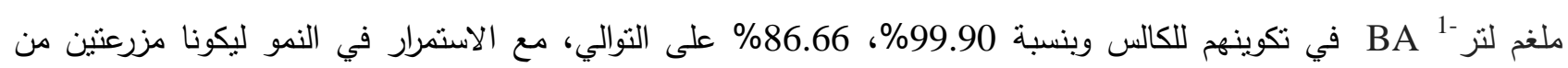

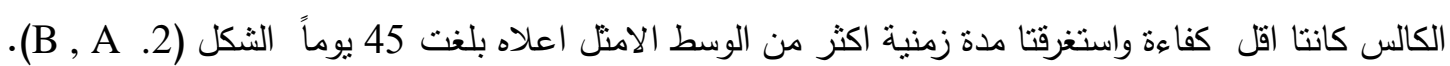
وكان لإضافة الاوكسينات الى الاوساط الحاوية على BA فقط دوراٌ هاماً في تحفيز استحداث الكالس. اذا كانت نسبته في وسط MS الحاوي على 2.0 ملغم لتز - BA فقط صفر \% ولكن سجلت النسب في ذات الوسط ولكن بعد دعمه بإضافة 2.0 ، 2.0

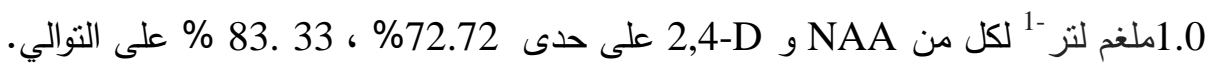
واعطت قطع الاوراق استجابة ضعيفة لاستحداث الكالس. اذ لم تتجح الا في 6 اوساط فقط أفضلها كان في وسط 1.5 ملغم لنز -1 لكل من فمع الارف تتتج مزارع من الكالس. 


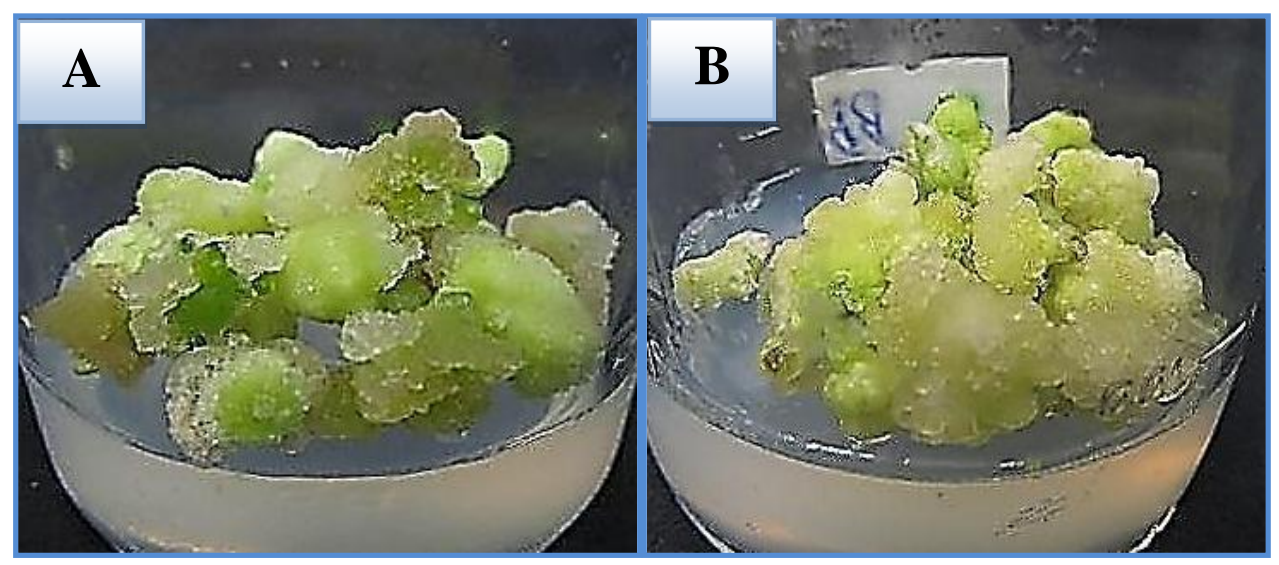

الشكل 2: انتاج مزارع كالس السيقان تحت الفلقية لبادرات نبات البروكلي Brassica oleracea var. italica ويعمر 45 يوما والنامية على سطح وسط MS

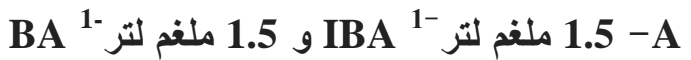

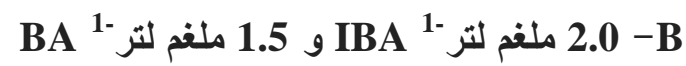

Brassica oleracea var. italica التكوين التلقائي للأفرع الخضرية من كالس السيقان تحت القلقية لبادرات نبات البروكلي من الملاحظات المميزة في هذه الدراسة وبعد 10 ايام من اعادة الزراعة الاولى لكالس السيقان تحت الفلقية والنامي على

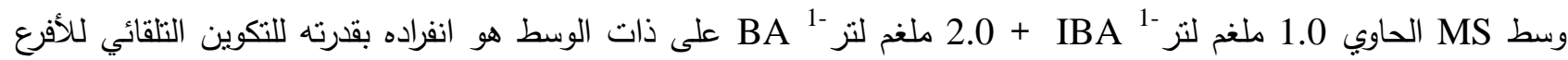

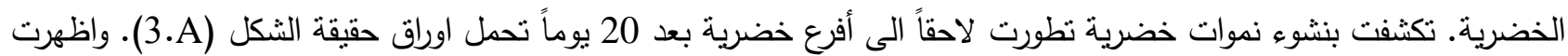

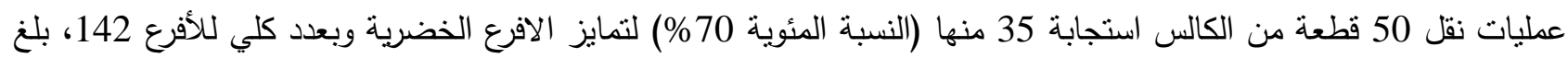
معدل اعدادها 4.05 فرع / قطعة واطوالها 2-3 سم وبوجود 3 -4 ورقة على كل فرع.

تجذير الافرع الخضرية المتكونة تلقائيا اظهرت البيانات سهولة تجذير الافرع الخضرية المنمايزة تلقائياً من كالس السيقان تحت الفلقية المستأصلة والمزروعة عمودياً داخل وسط MSO الصلب بكامل او نصف قوته التركيبية (الجدول 2)

الجدول 2: تجذير الافرع الخضرية المتمايزة تلقائياً للبروكلي Brassica oleracea var. italica وتكوين النباتات الكاملة في

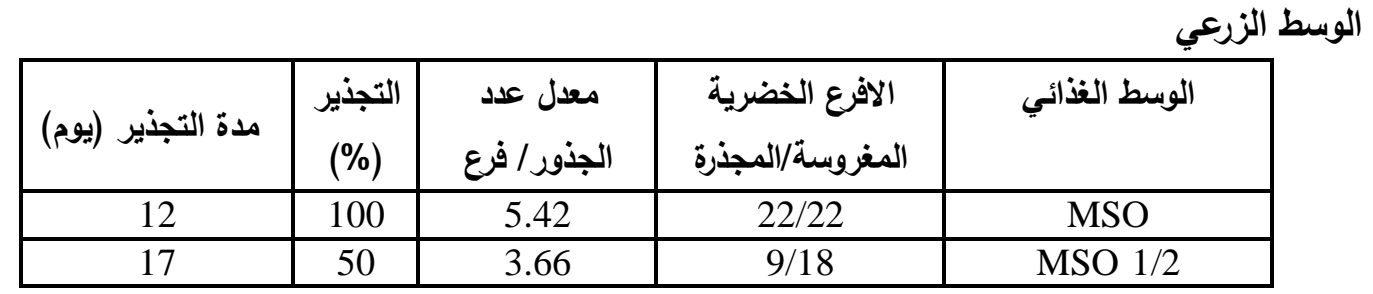


تفوق وسط MSO بكامل قوته التركيبية في نشوء الجذور من الافرع الخضرية المغروسة فيه وبنسبة 100\% بعد 12 يوماً منتجة نباتات كاملة الثكل (B.3). استمرت الافرع بالنمو مكونة شبكة من الجذور واتصفت بأثكالها الخيطية المتفرعة ولونها الابيض بعد 18 يوما الثكل (C.C). في حين ابدى وسط MSO بنصف قوته التركيبية قدرة مختزلة الى النصف في تكوين الجذور وابدت الجذور تأخيراً في نشوئها.

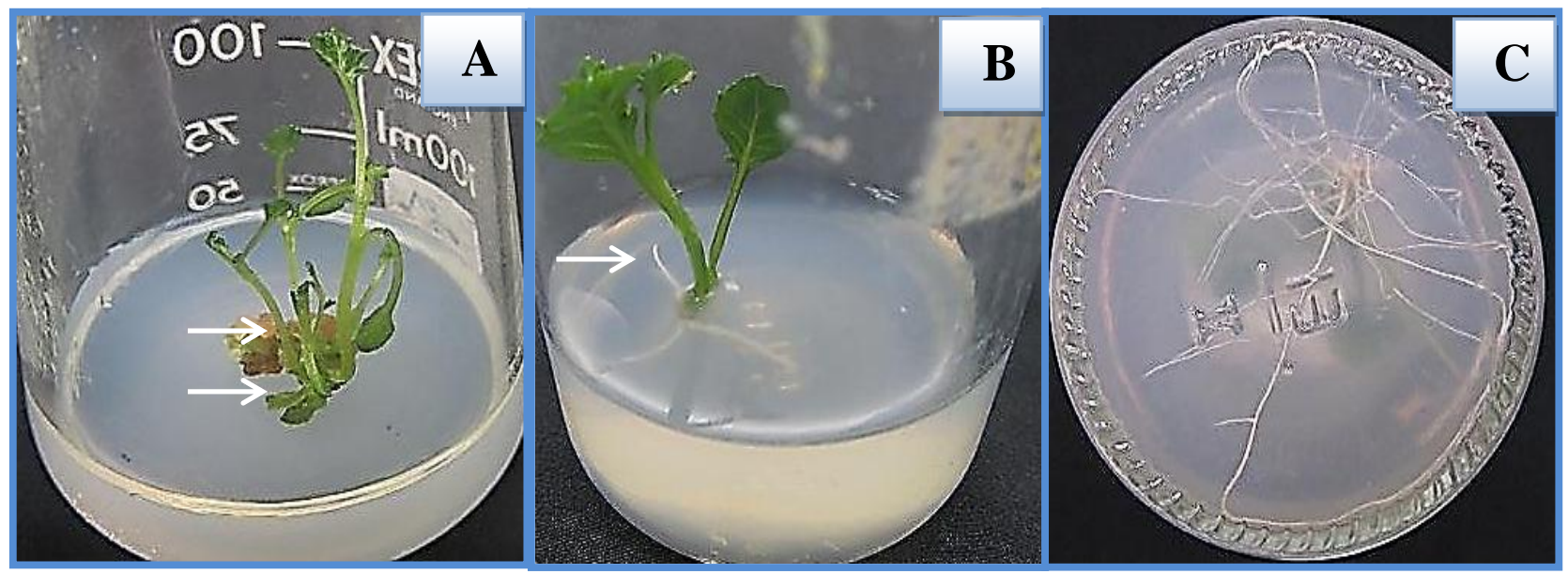

الثكل 3: تكوين نباتات البروكلي الكاملة من تمايز كالس السيقان تحت القلقية لبادراتها تحت الفلقية وتجذيرها في الوسط الزرعي

A التكوين التلقائي للأفرع الخضرية من كالس السيقان تحت القلقية النامي على وسط MS

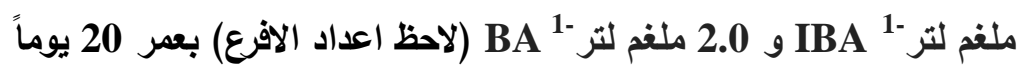
- B تجذير احد الافرع المستأصلة من (A) في وسط MSO بكامل قوته التركيبية بعد 12 يوماً (لاحظ الجذور المتكونة) -C

اقلمه نباتات البروكلي الناتجة من تمايز كالس السيقان تحت القلقية ونقلها الى التربة اظهرت عملية اقلمه نباتات البروكلي الناتجة من تمايز كالس السيقان تحت الفلقية نجاحها من خلال رفعها من الوسط الغذائي الثكل (A.4)، وغرسها في اوعية بلاستيكية شفافة مثقبة من الاسفل تحوي على تربة مزيجية وبتموس بنسبة 1:1

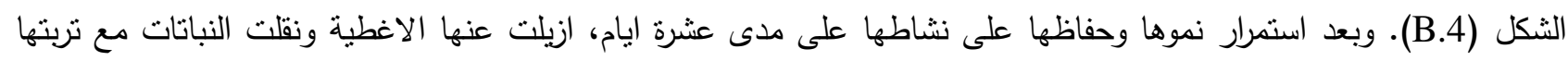
الى سنادين حاوية على ذات المزيج الثكل (C.4) وحفظت في ظروف غرفة الزهات الزروعات، ثم نقلت الى البيت الزجاجي لمتابعة نموها وقد اظهرت هذه النباتات قدرتها على تحمل الظروف البيئية والنمو. 


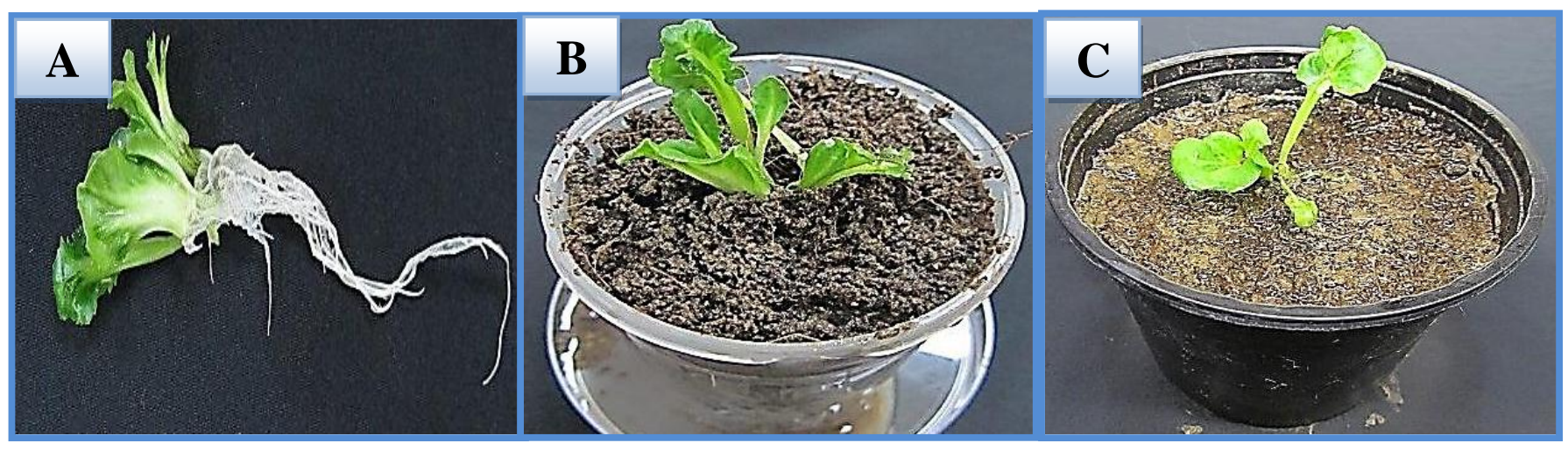

الثكل 4: اقلمه نباتات البروكلي Brassica oleracea var. italica المتمايزة من كالس السيقان تحت القلقية لبادراتها

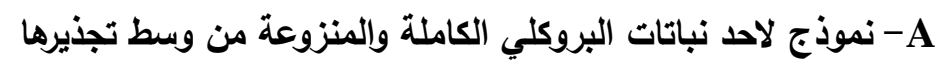

- النبات في (A) نامي في مزيج التربة والبتموس في وعاء بلاستيكي بعمر 17 يوماً -C نبات البروكلي بعمر 40 يوم نامي في مزيج التربة والبتموس داخل سندانه سعتها واحد كيلوغرام في ظروف البيت بليت الزجاجي

\section{المناقشة}

تعتمد كفاءة عملية تعقيم البذور على عدم تلوثها وانتاجها بادرات سليمة وذات حيوية عالية (Sen et al., 2013). ان التباين الواضح الذي اظهرته القطع النباتية المختلفة في استجابتها لاستحداث الكالس والفترة الزمنية اللازمة التي تقوقت فيها قطع بادرات السيقان تحت الفلقية على الاوراق ربما يعزى الى عدة عوامل منها وراثية او غير وراثية منل مصدر القطعة النباتية وحجمها

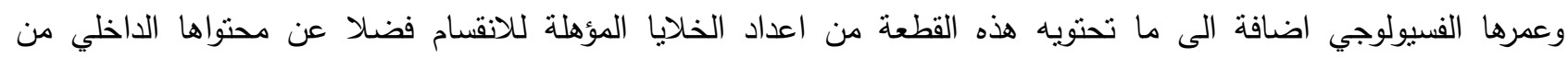

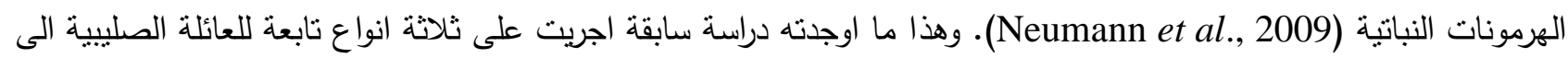
ان أفضل جزء نباتي لتكوين الكالس هو السيقان تحت الفقية (AL-Naggar et al., 2010). ان اضافة الاوكسينات بأنواعها الثلاثة 2,4-D ، NAA، الى الاوساط الغذائية لوحدها او متذاخلة مع BA كان له الدور البارز في استحداث الكالس من

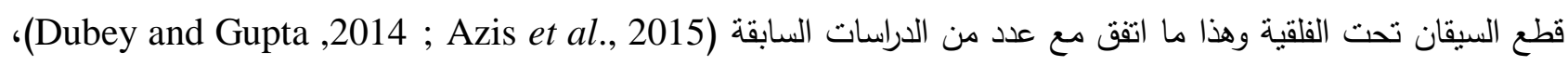

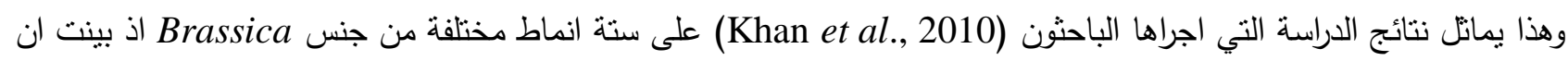

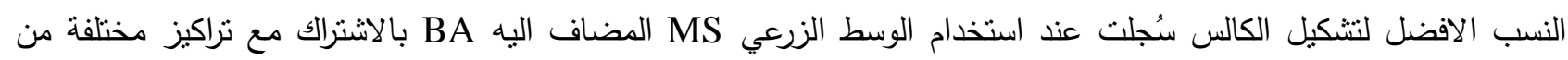
الاوكسينات. وكذلك ما نوصلت اليه الدراسات على نبات البروكلي الى ان أفضل وسط لاستحداث الكالس من الاجزاء النباتية

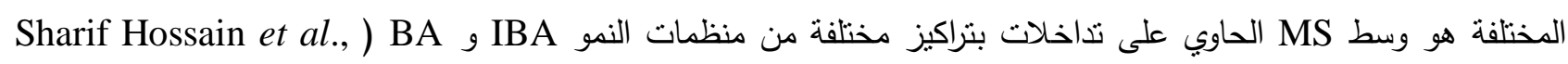
Sharif Hossain et al., 2016c ; 2016a من الهرمونات النباتية ومنظمات النمو المضافة الى الوسط (Azis et al., 2015 ; Juan et al., 2010). وقد يعزى التكوين التلقائي للأفرع الخضرية على وسط نمو الكالس ذاته الى النمط الوراثي للصنف النباتي المستخدم وبرهاناً على الطاقة الكامنة

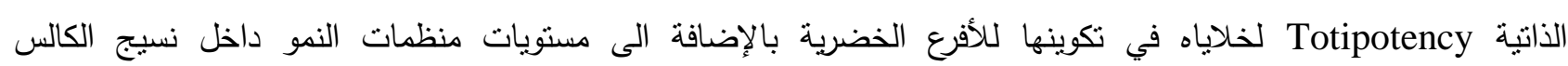
( Parray et al., 2018 ; Rajoriya et al., 2018) بكامل قوته التركييية قد يفسر بتواجد الاوكسينات الداخلية في القطع النباتية بكميات تمنحها القدرة على تكوين الجذور 
; Mohammed and Al-Mallah, 2013 ; Jennifer et al., 2004) فضلا عن دعم المكونات الكاملة من الوسط

.(Handayani, 2014

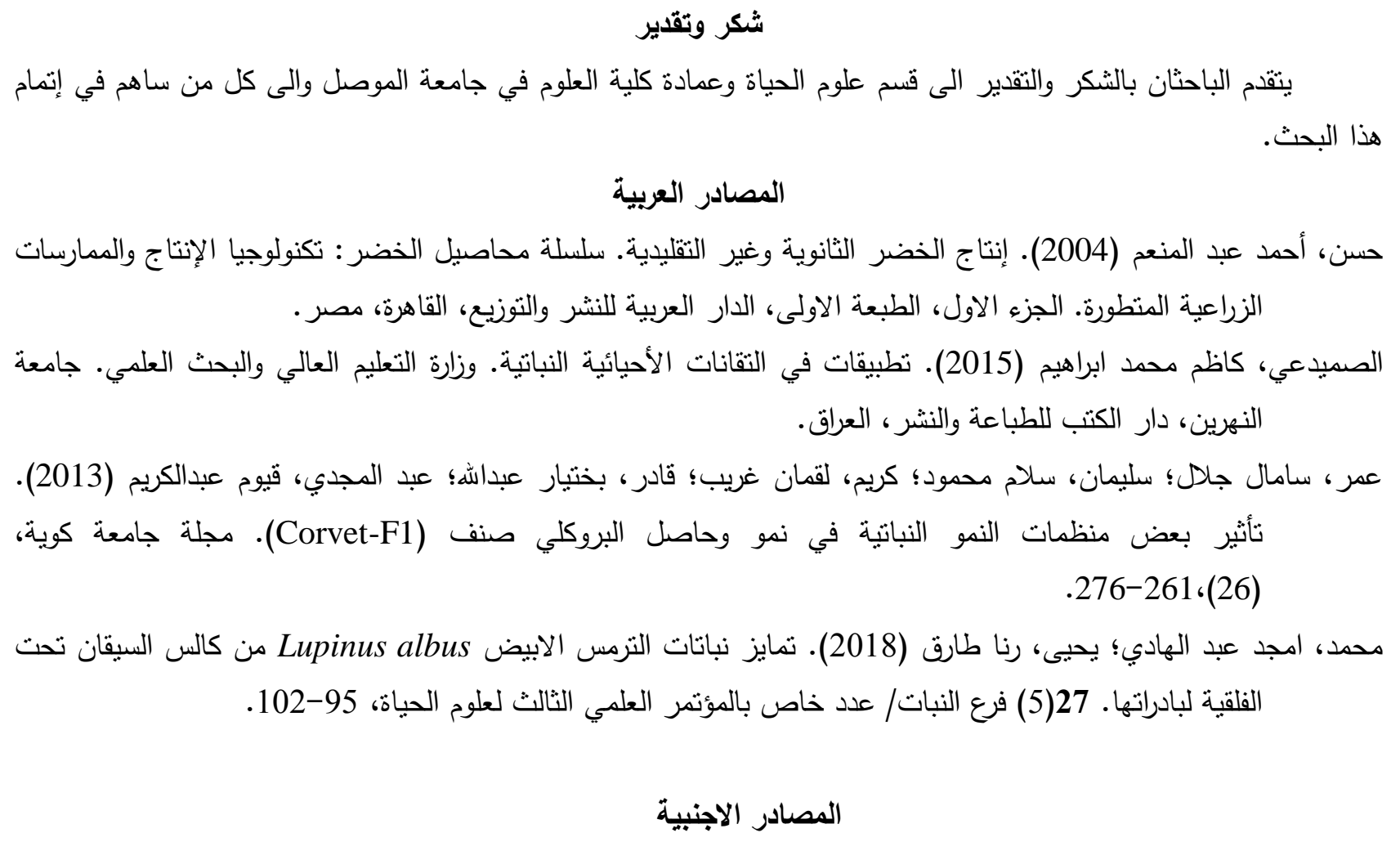

Al-Naggar, A.; Shabana, R.; Rady, M.; Ghanem, S.; Saker, M.; Reda, A.; Matter, M.; Eid, S. (2010). In Vitro callus initiation and regeneration in some canola varieties. Internet $J$. Academic Res., 2, 6-12.

Azis, N.A; Hasbullah, N.A.; Rasad, F.M.; Daud, N.F.; Amin, M.A.M.; Lassim, M.M. (2015). Organogenesis and growth response of Brassica oleracea var. italica through in vitro culture. International Conference on Agricultural, Ecological and Medical Sciences (AEMS-2015) April 7-8, 2015 Phuket (Thailand). 4-6.

Bejoy, M.; Dan, M.; Anish, N.; Nair, A.R.; Radhika, B.; Manesh, K. (2012). Micropropagation of an Indian ginger (Curcuma vamana Sabu and Mangaly): a wild relative of turmeric. Biotechnol., 11(6), 333-338.

Collen, H. A.; Edwards, S. (1998). "Plant Cell Culture". BIOS Scientific publishers LTD. UK.

Dubey, S.K.; Gupta, A.K. (2014). Callus induction and shoot proliferation from seedling explants of different mustard genotypes. Int. J. Curr. Microbiol. App. Sci., 3, 858-864.

Handayani, T. (2014). Regeneration of broccoli (Brassica oleracea L. var. bejo) from hybrid mature seed and molecular analysis of regenerants. $2^{\text {nd }}$ International Conference on Agricult. and Biotechn., 79(11), 57-6.1

Jennifer, N.; Janet, P.S.; Jerry, D.C. (2004). "Hormone Biosynthesis, Metabolism and its Regulation". In: Plant Hormones, Biosynthesis and Signal Transduction and Action, Peter, J.D. (Ed.). Kluwer Academic Publishers, UK., pp. 36-62.

Juan, L.; Lihua, W.; Jing, L.; Junhui, W. (2010). Effect of different plant growth regulators on callus induction in Catalpa bungei. Afric. J. Agri. Res., 5, 2699-2704.

Khan, M.; Robin, A.A.H.K.; Nazim-Ud-Dowla, M.; Talukder; S.; Hassan, L. (2010). In vitro regeneration potentiality of Brassica genotypes in differential growth regulators. Bangladesh J. Agricult. Res., 35, 189-199. 
Kim, S.J.; Park, W.T.; Uddin, M.R.; Kim, Y.B.; Nam, S.Y.; Jho, K.H.; Park, S.U. (2013). Glucosinolate biosynthesis in hairy root cultures of broccoli (Brassica oleracea var. italica). Nat. Prod. Commun., 8(2), 217-20.

Malabadi, R.B.; Teixeira da Silva, J.; Nataraja, K.; Vijaya, K. S.; Mulgund, G.S. (2011). Induction of somatic embryogenesis in mango (Mangifera indica L.). Internat. J. Biol. Technol., 2, 12-18.

Mohammed, A. A.; Al-Mallah, M.K. (2013). Determination of $\beta$-carotene in Carrot (Daucus carota L.) Plants Regenerated from Stems Callus. Raf. J. Sci., 24(3), 72-36.

Murashige, T.; Skoog, F. (1962). A revised medium for rapid growth and bioassay with tobacco tissue culture. Physiol. Plant., 15, 473-479.

Nazirwan (2015). In vitro shoot generation from cotyledon explant of Brassica Oleracea using BAP and NAA. Internat. J. Sci. Res., 6(39), 1795-1797.

Neumann, K.; Kumar, A.; Imani, J. (2009). "Plant Cell and Tissue Culture - A tool in Biotechnology". Springer-Verlag Berlin, Germany.

Owis (2015). Broccoli The green beauty: A review. J. Pharm. Sci. Res., 7(9), 696-703.

Parray, J.A.; Kamili, A.N.; Jan, S.; Mir, M.Y.; Shameem, N.; Ganai, B.A.; Abd_Allah, E.F.; Hashem, A.; Alqarawi, A.A. (2018). Manipulation of plant growth regulators on phytochemical constituents and DNA protection potential of the medicinal plant Arnebia benthamii. Bio. Med. Res. Internat., 1-8. Open access.

Rajoriya, P.; Singh, V.K.; Jaiswal, N.; Lall, R. (2018). Optimizing the effect of plant growth regulators on in vitro micro propagation of Indian red banana (Musa acuminata). $J$. Pharmacognosy and Phytoch., 1, 628-634.

Sen, M.K.; Jamal, M.A.M.; Nasrin, S. (2013). Sterilization factors affect seed germination and proliferation of Achyranthes aspera cultured in vitro. Environment Experiment Biol., 11, 119-123.

Sharif Hossain, A. B. M.; Haq, I.; Ibrahim, N.A.; Aleissa, M.S. (2016a). Callus cellproliferation from broccoli leaf slice using IBA and BAP in vitro culture: Its biochemical and antioxidant properties. Elsevier, Data in Brief, 6,214-220.

Sharif Hossain, A. B. M.; Haq, I.; Aleissa, M.S.; Ibrahim, N.A.; Rashid, K.B. (2016b). Callus cell proliferation and explants regeneration using broccoli shoot tip in vitro culture: biochemical and antioxidant properties. British J. App. Sci. Technol.,13(5), 1-8.

Sharif Hossain, A. B. M.; Haq, I.; Ibrahim, N.A.; Aleissa, M.S. (2016c). Cell proliferation using broccoli leaf cutting in vitro culture: Its biochemical and antioxidant properties. British Biotechnol. J.,11(2), 1-9.

Thapa, U.; Rair, R. (2012). Evaluation of sprouting broccoli (Brassica oleraceae var. italic) genotypes for growth, yield and quality. Internat. J. Agricult. Sci., 4 (7), 284-286.

Tilaar, W. (1990). Mikropropagasi Brokoli (Brassica oleracea L.var italica) dan Studi Aktivitas Enzim Proeksidase, Katalase dan Glutamatdehidrogenase selama Pembentukan Plantlet. S2 Thesis, Institute Technology Bandung/ Bandung/ Indonesian.

Torres, K.C. (1989). "Tissue Culture Techniques for Horticultural Crops". Chapman and Hall. New York.

Yagishita, Y.; Fahey, J.W.; Dinkova-Kostova, A.T.; Kensler, T.W. (2019). Broccoli or sulforaphane: Is It the Source or Dose That Matters? Molecules, 24(19), 3593.

Yoldas, F.; Ceylan, S.; Yagmur, B.; Mordogan, N. (2008). Effect of nitrogen fertilizer on yield quality and nutrient content in broccoli. J. Plant Nutr., 31, 1333- 1343. 


\title{
Regenerated of Broccoli (Brassica oleracea var. italica) Plants from Differentiation of the Hypocotyl Stems Callus of its Seedlings
}

\author{
Safwan J. Sultan \\ Amjad A. Mohammed \\ Department of Biology/College of Science/ University of Mosul
}

\begin{abstract}
The current study produced broccoli plants (Brassica oleracea var. italica) from the differentiation the hypocotyl stems callus of its seedlings and succeed of their adaptation and transferred to the soil. The results showed the difference in ratio of callus initiation with different type of plant growth regulators Naphthalene acetic acid (NAA), 2,4-Dichlorophenoxyacetic acid (2,4-D), Indole-3-butyricacid (IBA), Benzyl adenine (BA) and their concentrations which used in this study. The interaction of IBA and BA had an efficient role of increasing the initiation ratios. Murashige and Skoog (MS) medium supplemented with $1.0 \mathrm{mg} \mathrm{L}^{-1} \mathrm{IBA}$ and $2.0 \mathrm{mg} \mathrm{L}^{-1}$ BA superiority in registered initiation ratio reached $100 \%$ after 11 days of the cultivation, and with its continued growth it produced typical callus cultures. The continued of callus subculture on the same initiation medium led to spontaneous production of 142 shoots produced from 50 pieces of callus. These regenerated shoots easily rooted in the MSO medium with full strength at ratio $100 \%$, and with continued growth and formation of efficient root groups, they were successfully adapted to the soil within the pots in the greenhouse.
\end{abstract}

Keywords: broccoli, callus cultures, spontaneous differentiation of shoots, adaptation. 